Provided for non-commercial research and education use. Not for reproduction, distribution or commercial use.

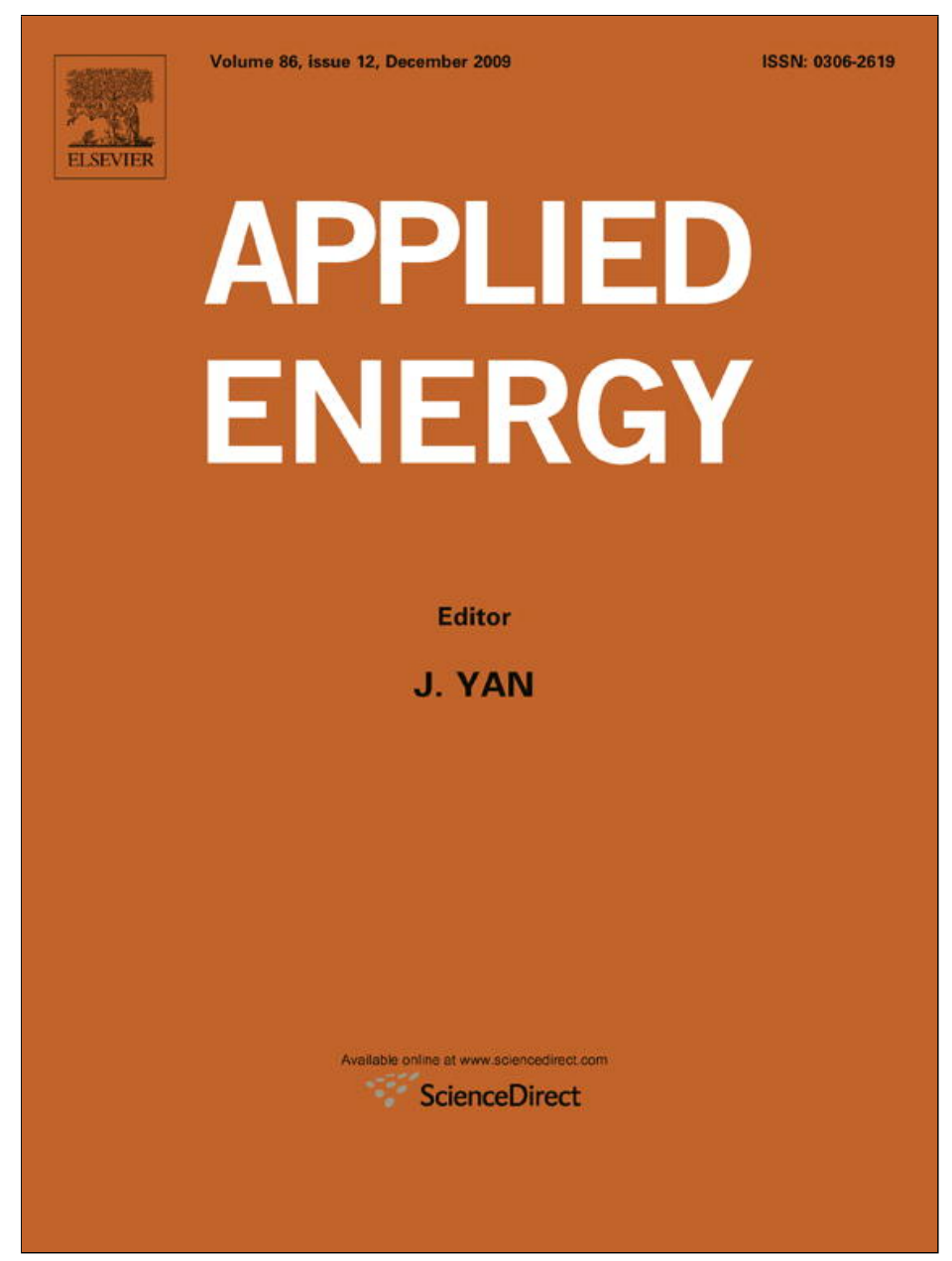

This article appeared in a journal published by Elsevier. The attached copy is furnished to the author for internal non-commercial research and education use, including for instruction at the authors institution and sharing with colleagues.

Other uses, including reproduction and distribution, or selling or licensing copies, or posting to personal, institutional or third party websites are prohibited.

In most cases authors are permitted to post their version of the article (e.g. in Word or Tex form) to their personal website or institutional repository. Authors requiring further information regarding Elsevier's archiving and manuscript policies are encouraged to visit:

http://www.elsevier.com/copyright 


\title{
Numerical simulation of three-dimensional flow dynamics in a hot water storage tank
}

\author{
Simon Ievers ${ }^{\mathrm{a}}$, Wenxian $\operatorname{Lin}^{\mathrm{a}, \mathrm{b}, *}$ \\ ${ }^{a}$ School of Engineering and Physical Sciences, James Cook University, Townsville, QLD 4811, Australia \\ ${ }^{\mathrm{b}}$ Solar Energy Research Institute, Yunnan Normal University, Kunming, Yunnan 650092, PR China
}

\section{A R T I C L E I N F O}

\section{Article history:}

Received 14 November 2008

Received in revised form 31 March 2009

Accepted 1 April 2009

Available online 12 May 2009

\section{Keywords:}

Numerical simulation

Hot water storage tank

Three-dimensional fluid dynamics

Exergy

Thermal stratification

\begin{abstract}
A B S T R A C T
A hot water storage device is one of the most common household appliances yet it is also one of the biggest sources of energy consumption. With natural resources fading, it is imperative that typical highenergy users such as hot water systems are made as energy efficient as possible. Research has shown that the thermal performance of a hot water system can be increased by maximising the level of thermal stratification within the storage tank, which could lead to huge energy saving. To analyse the effects of tank geometry and operating conditions on the thermal stratification within a storage tank, seven threedimensional models have been numerically simulated by using the computational fluid dynamics program Fluent with realistic boundary and initial conditions applied. The level of thermal stratification in each model has been quantified using exergy analyses. The results show that increasing the tanks height/diameter aspect ratio, decreasing inlet/outlet flow rates and moving the inlet/outlet to the outer extremities of the tank all result in increasing levels of thermal stratification.
\end{abstract}

(c) 2009 Elsevier Ltd. All rights reserved.

\section{Introduction}

A hot water storage device is used in almost every home in the world to provide a reliable source of hot water for sanitary or cooking purposes. It is also one of the biggest sources of energy consumption within a typical household and hence an improvement of its efficiency will have tremendous benefits for both the residents and the environments. There are currently three types of hot water systems in production: electric, gas and solar. Despite their apparent differences, all three systems share one major component, the hot water storage tank. This is where the hot water is stored in preparation for use.

It is a common misconception that the liquid within a hot water storage tank is a uniform temperature. In real situations, the cooler, denser fluid will settle towards the bottom of the tank while the hotter lighter fluid will rise to the top, providing that the water within the tank is not mixed or agitated in any way. This thermal stratification phenomenon is a highly desirable quality as it contributes significantly towards the storage tank's efficiency, increasing it by as much as $10 \%$ [1]. Because of the benefits of improving and maintaining thermal stratification, it has been the subject of many studies in recent years. For example, Furbo et al. [2] have shown that it is possible to achieve a $3 \%$ increase of the thermal

* Corresponding author. Address: School of Engineering and Physical Sciences, James Cook University, Townsville, QLD 4811, Australia. Tel.: +61 7 47815091; fax: +61747816788.

E-mail addresses: wenxian.lin@jcu.edu.au, wenxian1201@yahoo.com (W. Lin). performance of a system by simply using a two draw of levels in a tank instead of one fixed level draw off point; Hegazy and Diab [3] and Hegazy [4] have shown that using simple slotted diffusers of the inlet can lead to substantial increases in thermal performance; Lavan and Thompson [5] found experimentally that the location of the cold water inlet coming from the load was of greater importance than the location and geometry of the hot water extraction point. Bouhdjar and Harhad [6] found numerically that as the aspect ratio increased so did the thermal stratification and ultimate efficiency of the system; Altuntop et al. [7] shown that the Reynolds number should be kept well below the transition region $(<2100)$ to ensure laminar flow and to promote good thermal stratification. More detailed reviews on these previous studies can be found in recent theses by Perez [8] and Ievers [9].

A comprehensive review of literature has revealed that to date, most previous studies have been undertaken using costly experiments or very primitive one- or two-dimensional analytical models. Numerical studies, although currently mainly two-dimensional, are becoming more promising means to investigate the complex unsteady fluid dynamics within the water storage tank [8-12]. For example, Shin et al. [13] used numerical simulation to determine the effects of design parameters such as storage tank size, loading time, diffuser shape and inlet velocity and found that of all the factors affecting the thermal stratification and therefore performance of the system, the loading time appears to be the most influential and the inlet velocity seems to have little effect on the level of thermal stratification within the tank; Spall [14] used the CFD program Fluent to numerically investigated the 
natural stratification of turbulent flows in axi-symmetric, cylindrical, chilled water storage tank and shown that two-dimensional numerical predictions overestimate the thickness of the thermocline; Shah and Furbo [15] also used Fluent to investigate the effects of inlet design and demonstrated that the two-dimensional numerical simulation underestimated mixing within the tank, due to the laminar flow assumption. Recently, Perez [8] carried out three-dimensional numerical simulations on the unsteady laminar convection in cylindrical domains, demonstrating that it is feasible for the transient three-dimensional flow dynamics in a hot water storage tank to be modelled numerically using Fluent. With three-dimensional numerical simulations, it is expected that better understanding of the effects of varying tank geometry and fluid dynamics on the thermal stratification within the hot water storage system will be achieved, which will lead to the development of a more efficient design to optimize performance and cost efficiency. Furthermore, three-dimensional numerical models will provide more accurate and realistic results than the two-dimensional models and be more cost and time effective than conducting physical experiments.

The aim of this paper is to use three-dimensional numerical modelling techniques for simulating the transient three-dimensional fluid dynamics within the thermal energy storage tanks, with the view of improving thermal stratification and the overall efficiency of the system. More specifically, this paper will develop three-dimensional CFD models to quantify the level of thermal stratification in a tank and to investigate the effects of tank aspect ratio, inlet/outlet flow rate and inlet outlet position on the level of thermal stratification. It is believed that the outcome of this investigation will provide insight into the effects that these parameters have on thermal energy storage, which will be crucial for the maximization of the efficiency of a hot water storage tank.

\section{Methodology}

The three-dimensional fluid dynamics in a storage tank is described by the following Navier-Stokes and temperature equations, which are written in cylindrical coordinates with the Boussinesq assumption as:

$$
\begin{aligned}
& \frac{1}{r} \frac{\partial\left(r \rho u_{r}\right)}{\partial r}+\frac{1}{r} \frac{\partial\left(\rho u_{\theta}\right)}{\partial \theta}+\frac{\partial\left(\rho u_{z}\right)}{\partial z}=0 \\
& \frac{\partial u_{r}}{\partial t}+u_{r} \frac{\partial u_{r}}{\partial r}+\frac{u_{\theta}}{r} \frac{\partial u_{r}}{\partial \theta}-\frac{u_{\theta}^{2}}{r}+u_{z} \frac{\partial u_{r}}{\partial z}=-\frac{1}{\rho} \frac{\partial P}{\partial r} \\
& +v\left[\frac{1}{r} \frac{\partial}{\partial r}\left(r \frac{\partial u_{r}}{\partial r}\right)-\frac{u_{r}}{r^{2}}+\frac{1}{r^{2}} \frac{\partial^{2} u_{r}}{\partial \theta^{2}}-\frac{2}{r^{2}} \frac{\partial u_{\theta}}{\partial \theta}+\frac{\partial^{2} u_{r}}{\partial z^{2}}\right] \\
& \frac{\partial u_{\theta}}{\partial t}+u_{r} \frac{\partial u_{\theta}}{\partial r}+\frac{u_{\theta}}{r} \frac{\partial u_{\theta}}{\partial \theta}+\frac{u_{r} u_{\theta}}{r}+u_{z} \frac{\partial u_{\theta}}{\partial z}=-\frac{1}{\rho r} \frac{\partial P}{\partial \theta} \\
& +v\left[\frac{1}{r} \frac{\partial}{\partial r}\left(r \frac{\partial u_{\theta}}{\partial r}\right)-\frac{u_{\theta}}{r^{2}}+\frac{1}{r^{2}} \frac{\partial^{2} u_{\theta}}{\partial \theta^{2}}+\frac{2}{r^{2}} \frac{\partial u_{r}}{\partial \theta}+\frac{\partial^{2} u_{\theta}}{\partial z^{2}}\right] \\
& \frac{\partial u_{z}}{\partial t}+u_{r} \frac{\partial u_{z}}{\partial r}+\frac{u_{\theta}}{r} \frac{\partial u_{z}}{\partial \theta}+u_{z} \frac{\partial u_{z}}{\partial z}=-\frac{1}{\rho} \frac{\partial P}{\partial z}+\rho g \\
& +v\left[\frac{1}{r} \frac{\partial}{\partial r}\left(r \frac{\partial u_{z}}{\partial r}\right)+\frac{1}{r^{2}} \frac{\partial^{2} u_{z}}{\partial \theta^{2}}+\frac{\partial^{2} u_{z}}{\partial z^{2}}\right]
\end{aligned}
$$

$$
\frac{\partial T}{\partial t}+u_{r} \frac{\partial T}{\partial r}+\frac{u_{\theta}}{r} \frac{\partial T}{\partial \theta}+u_{z} \frac{\partial T}{\partial z}=\kappa\left[\frac{1}{r} \frac{\partial}{\partial r}\left(r \frac{\partial T}{\partial r}\right)+\frac{1}{r^{2}} \frac{\partial^{2} T}{\partial \theta^{2}}+\frac{\partial^{2} T}{\partial z^{2}}\right]
$$

where $r(\mathrm{~m}), \theta$ (degree) and $z(\mathrm{~m})$ are the coordinates in the radial, tangential and vertical directions, $u_{r}(\mathrm{~m} / \mathrm{s}), u_{\theta}(\mathrm{rad} / \mathrm{s})$ and $u_{z}(\mathrm{~m} / \mathrm{s})$ are the velocity components in these directions, $P(\mathrm{~Pa})$ is pressure, $g\left(\mathrm{~m} / \mathrm{s}^{2}\right)$ is the gravitation acceleration in the $z$ direction, $T(\mathrm{~K})$ is temperature, $\rho\left(\mathrm{kg} / \mathrm{m}^{3}\right), v\left(\mathrm{~m}^{2} / \mathrm{s}\right)$, and $\kappa\left(\mathrm{m}^{2} / \mathrm{s}\right)$ are the density, kinematic viscosity, and thermal diffusivity of fluid, respectively.

The computation domain and meshing have been created with Gambit and numerical simulations have been conducted by using the CFD solver Fluent. To analyse the numerical simulation data, a data interrogation software package Tecplot has been employed. Tecplot has a wide range of abilities including the ability to overlay the model with a variety of plots, including contour, $X-Y$ and sketches, the ability to dissect a model to see the inner flow patterns, which can be captured in 'snapshots' and then be animated to provide an excellent understanding of the flow evolution within the computational domain, and the ability to calculate specific parameters, such as the average temperature or energy on a user defined plane within the model. This last ability is particularly valuable for this paper when quantifying thermal stratification. In this paper, Tecplot has been used to create temperature contours from numerical simulation data to provide visual description of the transient flow evolution within the storage tank, in particularly the distinctive flow features like localised mixing and thermocline development. Tecplot has also been used to produce data for the exergy analysis which quantifies the level of thermal stratification within the tank. More detailed information about these packages can be found in $[16,9]$.

To quantify the thermal stratification, a number of different parameters/approaches have been proposed in the literature. Bahnfleth and Musser [17] defined a loss of capacity due to mixing and conduction through the course of a cycle. Khurana et al. [18] defined a dimensionless MIX number that is calculated as a function of the largest and smallest values of energy momentum considering an ideally stratified and completely mixed tank. Although this parameter considers the transient thermal nature of the inlet, it is only useful for comparing designs that have the same mass flow rate and thermal conditions. This parameter fails when considering different load strategies for the same geometry. Rosen [19] argued that traditional energy analysis may be inadequate as it cannot account for the degradation of the energy and proposed that the second law of thermodynamics offers an alternative measure of the quality of the energy stored. The process of the loss of stratification creates entropy through mixing and environmental losses and as a consequence, degradation of the energy stored. The instantaneous exergy within a storage tank is defined as:

$\epsilon=\int_{\Omega} \xi \rho d \Omega$

where $\epsilon$ is the instantaneous exergy (kJ), $\Omega$ is the volume of the storage $\operatorname{tank}\left(\mathrm{m}^{3}\right)$, and $\xi$ is the flow availability $(\mathrm{kJ} / \mathrm{kg})$, which is calculated by

$\xi=\left(h-h_{0}\right)-T_{o}\left(s-s_{0}\right)$

In which $h$ is enthalpy $(\mathrm{kJ} / \mathrm{kg}), h_{o}$ is the enthalpy at a reference state $(\mathrm{kJ} / \mathrm{kg}), s$ is entropy $(\mathrm{kJ} / \mathrm{kg} \mathrm{K}), s_{o}$ is the entropy at a reference state $(\mathrm{kJ} / \mathrm{kg} \mathrm{K})$, and $T_{o}$ is the temperature at a reference state $(\mathrm{K})$.

Rosen [19] defined an exergy-based non-dimensional parameter $\zeta$ to quantify the degree of thermal stratification in a tank by comparing it to two ideal extreme states, a perfectly stratified tank and a perfectly mixed tank. The non-dimensional exergy parameter $\zeta$ is defined as:

$$
\zeta=1-\frac{\epsilon-\epsilon_{\text {mix }}}{\epsilon_{\text {srat }}-\epsilon_{\text {mix }}}
$$

where $\epsilon_{\text {mix }}$ is the instantaneous exergy of a perfectly mixed tank (kJ) and $\boldsymbol{\epsilon}_{\text {srat }}$ is the instantaneous exergy of a perfectly stratified tank (kJ). $\zeta=0$ for a perfectly stratified tank and $\zeta=1$ for a perfectly 
mixed tank. For an actual tank with a non-perfect thermal stratification, $\zeta$ will be between 0 and 1 .

Assuming both density and specific heat are constants, the global instantaneous exergy difference between the actual tank and a perfectly mixed tank can be evaluated by

$\epsilon-\epsilon_{\text {mix }}=C_{p} \rho \Omega\left[\left(\bar{T}-T_{\text {mix }}\right)-T_{0} \ln \left(\widetilde{T} / T_{\text {mix }}\right)\right]$

where $C_{\mathrm{p}}$ is the specific heat of fluid $(\mathrm{J} / \mathrm{kg} \mathrm{K}), \bar{T}$ is the volume averaged temperature $(\mathrm{K})$, and $\tilde{T}$ is the equivalent temperature $(\mathrm{K})$. Similarly, the global instantaneous exergy difference between a perfectly stratified tank and a perfectly mixed tank can be evaluated by

$\epsilon_{\text {strat }}-\epsilon_{\text {mix }}=C_{p} \rho \Omega\left[\left(\bar{T}_{\text {strat }}-T_{\text {mix }}\right)-T_{0} \ln \left(\tilde{T}_{\text {strat }} / T_{\text {mix }}\right)\right]$

where $\bar{T}_{\text {strat }}$ and $\tilde{T}_{\text {strat }}$ are the volume averaged temperature and the equivalent temperature in a stratified tank $(\mathrm{K})$, respectively.

The mixed temperature $T_{m i x}$ is calculated using a net energy balance that includes energy losses to the ambient and net energy addition or withdrawal during the loading or unloading phases, as represented by the following equation:

$\rho C_{p} \Omega \frac{d T_{\text {mix }}}{d t}=\dot{m}_{\text {in }} C_{p \text { in }}\left(T_{\text {in }}-T_{\text {mix }}\right)-U S\left(T_{\text {mix }}-T_{\text {amb }}\right)$

where $U$ is the overall heat transfer coefficient $\left(\mathrm{W} / \mathrm{m}^{2} \mathrm{~K}\right), S$ is the surface area $\left(\mathrm{m}^{2}\right)$, and $T_{a m b}$ is the ambient temperature (K).

$\bar{T}$ is defined below, where the summation is extended into all the CV's (control volume),

$\bar{T}=\frac{1}{\Omega} \sum_{C V} T_{i} \Omega_{i}$

where $T_{i}$ is the temperature in the $i$ th $\mathrm{CV}(\mathrm{K})$ and $\Omega_{i}$ is the volume of the ith $\mathrm{CV}\left(\mathrm{m}^{3}\right)$.

Physically, $\tilde{T}$ represents the equivalent temperature of a mixed thermal energy system that has the same exergy as a stratified thermal energy system. It is defined as,

$\tilde{T}=\exp \left[\frac{1}{\Omega} \sum_{C V} \Omega_{i} \ln T_{i}\right]$

In a similar manner, $\bar{T}_{\text {strat }}$ and $\tilde{T}_{\text {strat }}$ are calculated by,

$\bar{T}_{\text {strat }}=\frac{1}{\Omega} \sum_{C V} T_{\text {strat }, i} \Omega_{i}, \quad \tilde{T}_{\text {strat }}=\exp \left[\frac{1}{\Omega} \sum_{C V} \Omega_{\text {strat }, i} \ln T_{i}\right]$

After extensive comparisons among these parameters/approaches with the numerical simulation data obtained for this paper, it is found that the non-dimensional exergy parameter best quantifies the level of thermal stratification in the storage tank, and hence it will be used in this paper as the parameter to quantify the level of thermal stratification in the tank.

\section{Results and discussions}

As the main objective of this paper is to use three-dimensional numerical simulations to investigate the effects of the height/ diameter aspect ratio of the thermal storage tank, the inlet and outlet locations of hot and cold water, the inlet/outlet mass flow rate, hence a series of three-dimensional numerical models have been developed.

\subsection{Three-dimensional numerical models}

The first numerical model that has been developed is the base model - 3D-1. All other numerical models that have been developed in this paper are derived from this base model to demonstrate the effects of various configuration and operating parameters. The base model has been developed in this paper based on a $250 \mathrm{~L}$ Rinnai split system 316 stainless steel hot water storage tank [20]. It has the following physical dimensions: external tank height $1690 \mathrm{~mm}$, external tank diameter - $600 \mathrm{~mm}$, internal tank height $1250 \mathrm{~mm}$, internal tank diameter $-500 \mathrm{~mm}$, inlet/outlet water pipe diameter $-15 \mathrm{~mm}$, and insulation thickness $-50 \mathrm{~mm}$. As the designed mass flow rate of hot/cold water that is charged/discharged to/from the tank for the Rinnai base model is not specified, the flow rate of $\dot{m}=0.05 \mathrm{~kg} / \mathrm{s}$ recommended by Garg et al. [1] has been assumed for this base model 3D-1. This flow rate leads to the Reynolds number of 4224 under normal operating conditions.

The internal storage tank of this Rinnai which has the height/ diameter aspect ratio (AR) of 2.5 has been reproduced in Gambit, as shown in Fig. 1, to serve as the computational domain for the subsequent numerical simulations. To ensure realistic results were produced, accurate boundary conditions were applied. These include that no-slip (all velocity components are zero) and adiabatic (all temperature gradients) boundary conditions are applied on all solid surfaces within the tank; at the inlet, fixed and uniform temperature and velocity are specified; and at the outlet, the gradients of both temperature and velocity are set to be zero. For each simulation, initially (at $t=0$ ), these is no flow within the tank and the water inside the tank is at a uniform temperature $T_{0}$ and is quiescent (all velocity components anywhere within the tank are zero).

To investigate the effect of varying AR on the level of thermal stratification within the tank, three-dimensional numerical models 3D-2 and 3D-3 have been developed. To accurately assess the effect of varying aspect ratios, the water capacity of the storage tanks of models 3D-2 and 3D-3 must be the same as the base model 3D-1 (that is $250 \mathrm{~L}$ ), and hence the diameters and heights of the tanks will be varied for these two models. Model 3D-2 has the internal height of $1420 \mathrm{~mm}$ and internal diameter of $473 \mathrm{~mm}$, resulting in the aspect ratio of $A R=3$, and model $3 \mathrm{D}-3$ has the internal height of $1996 \mathrm{~mm}$ and internal diameter of $399 \mathrm{~mm}$, resulting in the aspect ratio of $A R=5$.

To examine the effects of varying mass flow rate of hot/cold water that is charged/discharged to/from the tank on the level of thermal stratification within the storage tank, numerical models 3D-4 and 3D-5 have been developed. It should be noted that both the physical system and the corresponding numerical model for models 3D-4 and 3D-5 are exactly the same as the base system/ model. The only differences are the mass flow rates of hot/cold water charged/discharged. The mass flow rates for models 3D-4 and $3 \mathrm{D}-5$ are $0.10 \mathrm{~kg} / \mathrm{s}$ and $0.15 \mathrm{~kg} / \mathrm{s}$, respectively, resulting in the Reynolds number of 8448 and 12,672.
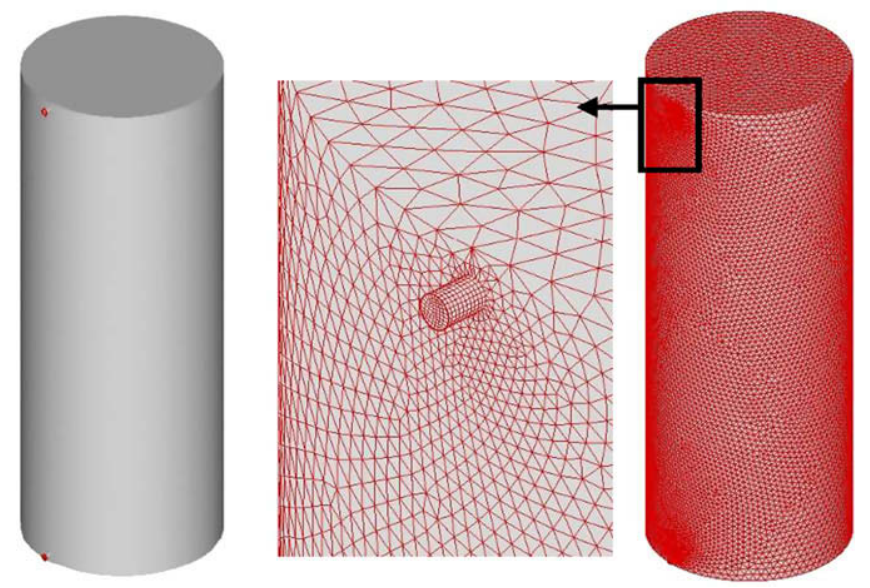

Fig. 1. The typical physical system (left) and the corresponding numerical mode with mesh distribution (right). 
To study the effects of the inlet/outlet position of hot/cold water which is charged/discharged to/from the tank on the extent of thermal stratification within the storage tank, models 3D-6 and 3D-7 have been developed. These two models have the same overall tank geometry of the base model (3D-1), and the only difference is that both the inlet and outlet have been moved to the positions $150 \mathrm{~mm}$ and $300 \mathrm{~mm}$ away from the top/bottom of the internal tank for model 3D-6 and model 3D-7, respectively. In the base model 3D-1, both the inlet and outlet have been located $20 \mathrm{~mm}$ away from the top/bottom of the internal tank.

The computational domain has been modelled in Gambit as three distinct volumes: a large cylinder for the storage tank and smaller cylinders for the inlet and outlet pipes. This allowed the storage tank to be modelled with relatively coarse elements, while the smaller inlet/outlet pipes could have a much finer mesh applied. If the domain had consisted of a single volume, a very large number of small elements would have been required to mesh it as the mesh size would have to be chosen based on the size of the inlet/outlet pipes. Meshing the three volumes separately allows a dramatic reduction of the amount of elements in the domain, leading to realistic computational times while maintaining accuracy of the numerical simulations.

Both the inlet and the outlet pipes consist of 640 hexahedron elements meshed using the cooper scheme. When applying the hexahedron mesh using the cooper scheme, Gambit treats the volume as consisting of one or more logical cylinders, each of which consists of two source faces and a barrel. Gambit firstly meshes the source faces, and then sweeps the mesh through the volume. This allows the formation of a uniform mesh with no highly skewed elements. As the flow inside the inlet/outlet will not be considered when analysing the results, there was no need for any boundary layer refinement. The main storage tank volumes have been meshed using a combination of tetrahedral and hybrid elements using the $T_{\text {grid }}$ scheme. Considerable time was devoted trying to apply hexahedral elements and the cooper scheme to this volume due to the fact that it greatly reduces instances of skewed elements that can provide inaccurate results. As applying this scheme proved unsuccessful due to the side location of the inlet/ outlet, it was decide the tet/hybrid elements and $T_{\text {grid }}$ scheme would provide comparable results as mesh swapping and smoothing can be applied, reducing the instances of skewed elements. When meshing using tet/hybrid elements and the $T_{\text {grid }}$ scheme, Gambit attempts to produce a mesh that consists primarily of tetrahedral mesh elements, however it may also contain hexahedral, pyramidal and wedge elements where appropriate. It is beneficial as it can be applied to almost any volume. The mesh for models 3D-1, 3D-4, 3D-5, 3D-6 and 3D-7 consists of 272,725 elements, and that for models 3D-2 and 3D-3 are 259,565 and 312,120 elements, respectively, as summarized in Table 1 . These meshes have been selected after an extensive mesh dependence test [9].

For all cases considered, the numerical simulations run for the amount of time required to complete one cycle of water through the storage tank. The inlet temperature of water has been set to be $333.2 \mathrm{~K}$. After a series of time-step-dependence tests [9], it has been found that a time step of $0.5 \mathrm{~s}$ and accordingly a total number of time steps of 10,000 are optimal values which have then been used for all numerical simulations conducted in this paper.

\subsection{Evolution of transient temperature contours}

\subsubsection{Base model 3D-1}

The evolution of both the three-dimensional (3D) and the sectioned two-dimensional (2D) temperature contours for this base model over the time period of $250-2750 \mathrm{~s}$ are presented in Fig. 2. From this figure, it is seen that although the inlet mass flow rate is quite small $(0.05 \mathrm{~kg} / \mathrm{s})$, a small amount of mixing still occurs in the upper regions of the tank, mainly during the first $1500 \mathrm{~s}$ of operation. At the beginning of operation, because the whole tank is cold, the sudden charge of hot water into the tank provokes mixing between the hot and the cold layers. It is also seen that the inlet jet has sufficient velocity to impact the back side of the tank causing the hot water to curl around the sidewalls before diffusing into the colder fluid. Because the fluid mass flow rate is small and the inlet is at the very top of the tank, it is reasonable to believe that most of the initial mixing can be attributed to diffusion between the hot and the cold water at the inlet rather than the inlet mass flow. In addition, as the hot water is already at the very top of the cold fluid, the buoyancy effect of hot water has a minimum effect on the level of mixing in this model.

As time progresses, three distinct thermal layers begin to develop inside the tank, which are clearly visible in both the 3D and sectioned 2D contours. A body of water at the hot inlet temperature begins to build at the top of the tank, while a large body of water at initially lower temperature remains on the bottom. Separating these two layers is a region of water that has a distinct thermal gradient driven by heat conduction from the hot layer to the cold layer. As the tank fills with hot water the conduction layer maintains almost the same thickness as it travels down the height of the tank. Due to the assumption that the tank walls could be considered adiabatic due to heavy level of insulation, there are no convection currents which would destroy the thermal layers. This means that as time progresses, the base model experiences little degradation of the level of thermal stratification within the tank.

The evolution of the vertical profiles of the averaged temperature in the tank is presented in Fig. 3 for the base model 3D-1, which indicates that the thermocline develops in the relatively early stages of the tanks operation. The steep, almost linear, parallel spacing of the temperature profiles is indicative of well defined thermoclines, indicating a good degree of thermal stratification with little mixing.

\subsubsection{Aspect ratio models $3 D-2$ and $3 D-3$}

As stated above, model 3D-2 and 3D-3 are used to examine the effects of the tank aspect ratio. These two models maintain the same loading and boundary and initial condition of 3D-1, however the aspect ratios of the tank have been increased from 2.5 to 3 and 5 , respectively. The evolutions of both the $3 \mathrm{D}$ and the sectioned $2 \mathrm{D}$ temperature contours for the model $3 \mathrm{D}-2(\mathrm{AR}=3)$ and the model

Table 1

Summary of the seven models under consideration.

\begin{tabular}{|c|c|c|c|c|}
\hline Model & Aspect ratio (AR) & Flow rate $(\dot{m}, \mathrm{~kg} / \mathrm{s})$ & Inlet/outlet position $(\Delta H \mathrm{~mm})$ & Mesh elements \\
\hline 3D-1: Base model & 2.5 & 0.05 & 20 & 272,725 \\
\hline 3D-2: AR $=3$ model & 3.0 & 0.05 & 20 & 259,565 \\
\hline 3D-3: AR = 5 model & 5.0 & 0.05 & 20 & 312,120 \\
\hline $3 \mathrm{D}-4: \dot{m}=0.10$ model & 2.5 & 0.10 & 20 & 272,725 \\
\hline 3D-5: $\dot{m}=0.15$ model & 2.5 & 0.15 & 20 & 272,725 \\
\hline 3D-6: $\Delta H=150$ model & 2.5 & 0.05 & 150 & 272,725 \\
\hline 3D-7: $\Delta H=300$ model & 2.5 & 0.05 & 300 & 272,725 \\
\hline
\end{tabular}



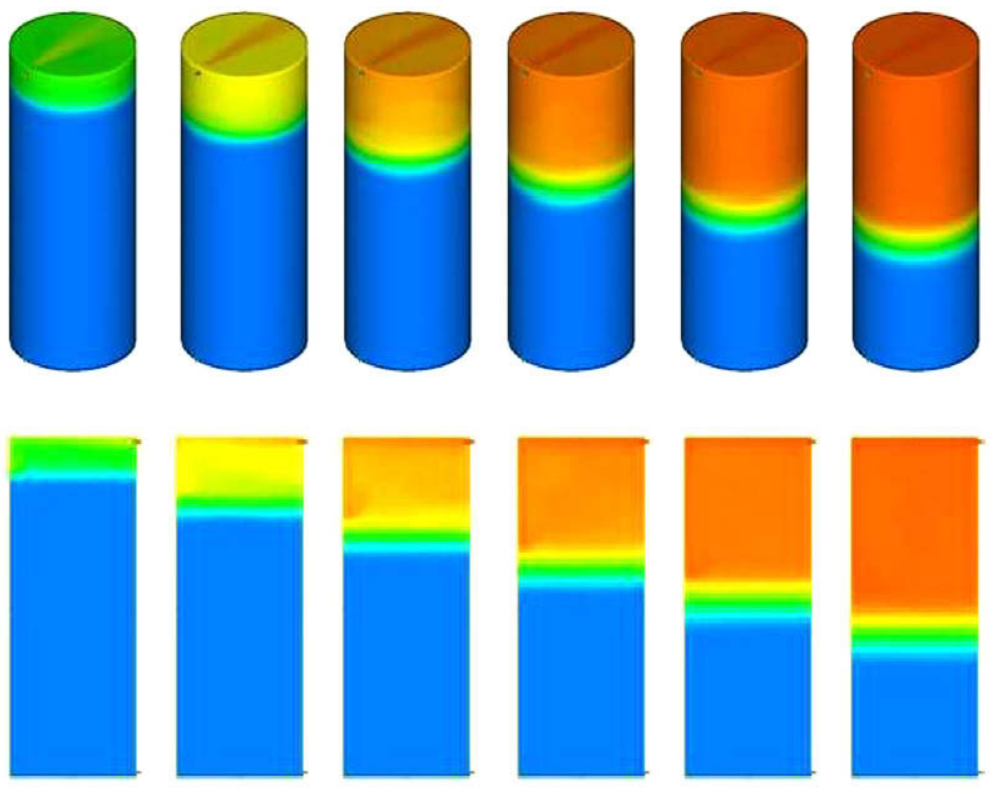

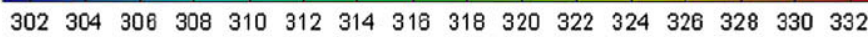

Fig. 2. Evolution of temperature contours of the base model 3D-1 from $250 \mathrm{~s}$ to $2750 \mathrm{~s}$ with $500 \mathrm{~s}$ increment (from left to right): top row - three-dimensional, and bottom row - sectioned two-dimensional.

3D-1 Transient Temperature Profiles

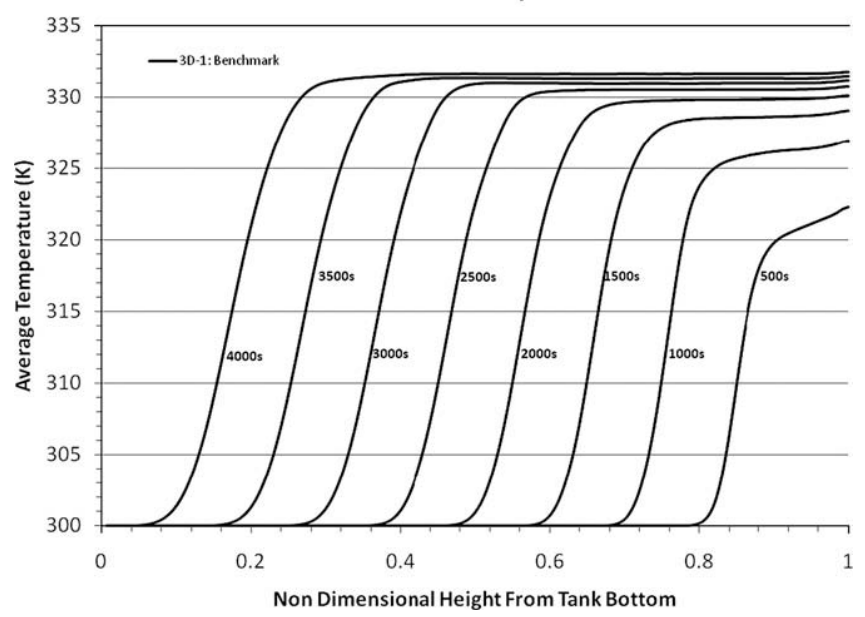

Fig. 3. Evolution of the vertical profiles of the averaged temperature in the tank for the base model 3D-1.

3D-3 (AR $=5$ ) over the time period of $250-2750 \mathrm{~s}$ are presented in Figs. 4 and 5, respectively.

Visually, the temperature contours of model 3D-2 are almost indistinguishable from that of 3D-1. There is a small amount of mixing initially present as the hot inlet water enters the cold fluid and diffuses. Like model 3D-1, the temperature contours inside the tank rapidly forms three distinct layers. The hot/cold water layers are thicker than that of 3D-1 due to the increased height of the tank. The conduction layer in the centre of the tank, however, maintains a similar thickness until the flow in the tank approximately reaches steady state after $5000 \mathrm{~s}$ of operation.

Like 3D-2, model 3D-3 has very similar temperature contours to the base model 3D-1. However, visually there appears to be less mixing during the initial injection of hot water. Three distinct lay- ers are developed at approximately $1000 \mathrm{~s}, 500 \mathrm{~s}$ earlier than the previous two models. This reduced mixing can be attributed to the smaller diameter of the tank, which allows a body of hot water to build in the top of the model much more quickly and consequently minimizes mixing during the early stages of the flow time. Although the three layers appear much more quickly, the width of the conduction layer is approximately the same as that in the base model, indicating that the levels of thermal stratification are comparable.

The evolutions of the vertical profiles of the averaged temperature in the tank for the aspect ratio models 3D-2 and 3D-3 are compared to that of the base model 3D-1 in Fig. 6. The linearity and steep gradients of the temperature profiles for both models 3D-2 and 3D-3 indicate well developed thermoclines with relatively small thicknesses. This indicates that models 3D-2 and 3D-3 have very little mixing and are well stratified. Another indication of a high level stratification in these aspect ratio models 3D-2 and $3 \mathrm{D}-3$ is that the temperatures in the top layers are approximately the same during the later stages of the flows.

\subsubsection{Mass flow rate models $3 D-4$ and $3 D-5$}

Models 3D-4 and 3D-5 have been developed to investigate the effects of the inlet/outlet mass flow rate on the thermal stratification within the storage tank. These models has the same geometry as model 3D-1 has, however, they have higher mass flow rates of $0.1 \mathrm{~kg} / \mathrm{s}$ and $0.15 \mathrm{~kg} / \mathrm{s}$, respectively. The evolutions of both the 3D and the sectioned 2D temperature contours for these two models over the time period of $100-1100 \mathrm{~s}$ are presented in Figs. 7 and 8 , respectively.

Unlike the aspect ratio models 3D-2 and 3D-3, it can be seen from Fig. 7 that the inlet/outlet mass flow rate has a significant effect on the level of thermal stratification within the tank. Although the three-layer structure is also developed in model 3D-4 as in the previous models, the upper hot layer is of a much lower temperature, indicating a large degree of mixing. When the inlet/outlet mass flow rate is increased, the inlet jet has considerably larger 

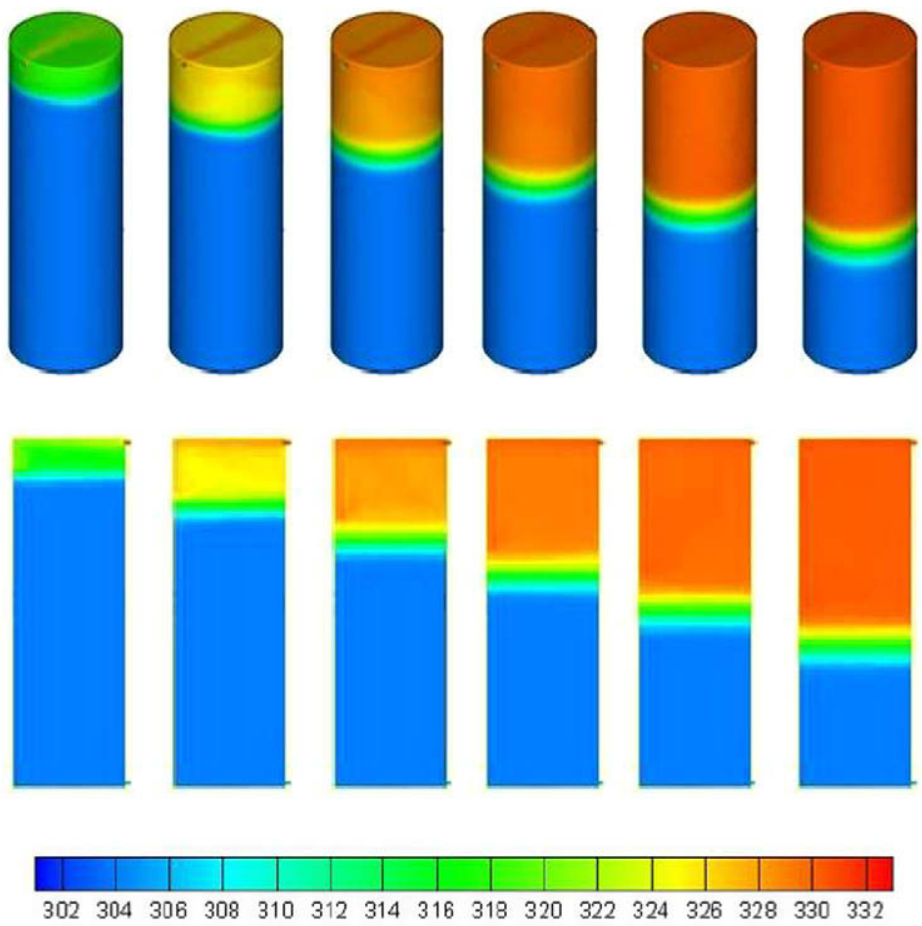

Fig. 4. Evolution of temperature contours of the 3D-2 model from $250 \mathrm{~s}$ to $2750 \mathrm{~s}$ with $500 \mathrm{~s}$ increment (from left to right): top row - three-dimensional, and bottom row sectioned two-dimensional.
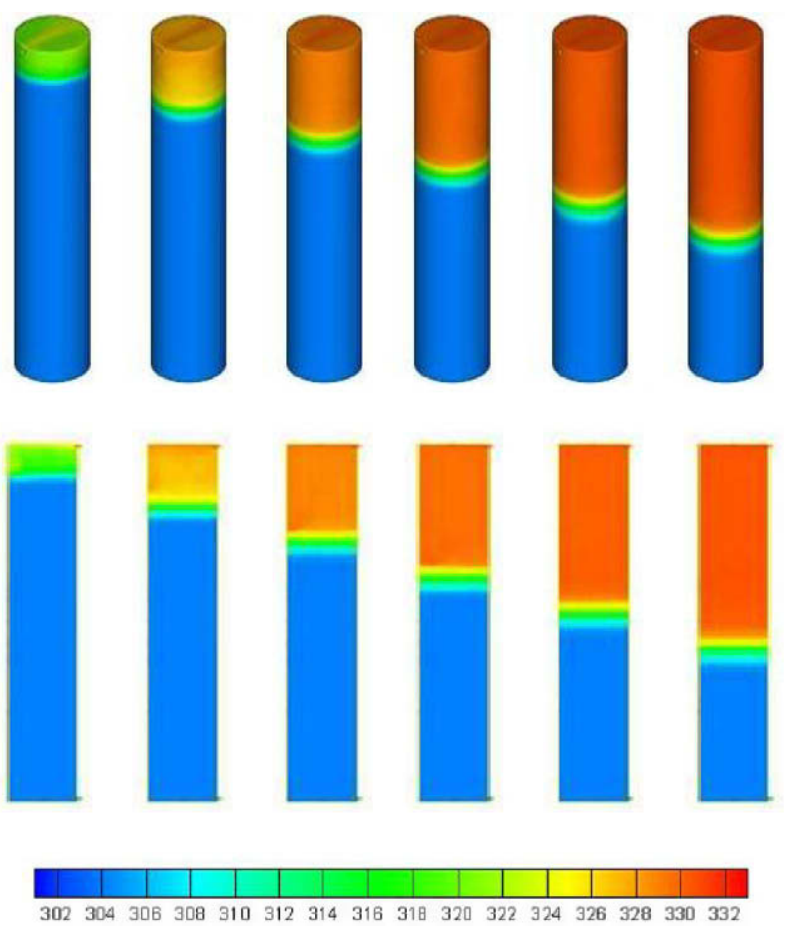

Fig. 5. Evolution of temperature contours of the 3D-3 model from $250 \mathrm{~s}$ to $2750 \mathrm{~s}$ with $500 \mathrm{~s}$ increment (from left to right): top row - three-dimensional, and bottom row - sectioned two-dimensional.

momentum, resulting in stronger striking on the opposite surface and dispersing of the hot fluid into a larger area before it diffuses. Consequently, the water in the tank stays well mixed and by the end of the simulations, the temperatures in the top layer is approximately $6^{\circ}$ cooler than that observed in the base model 3D- 1 .

The effect of inlet/outlet mass flow rate on the thermal stratification in the tank is especially evident when examining Fig. 8 for

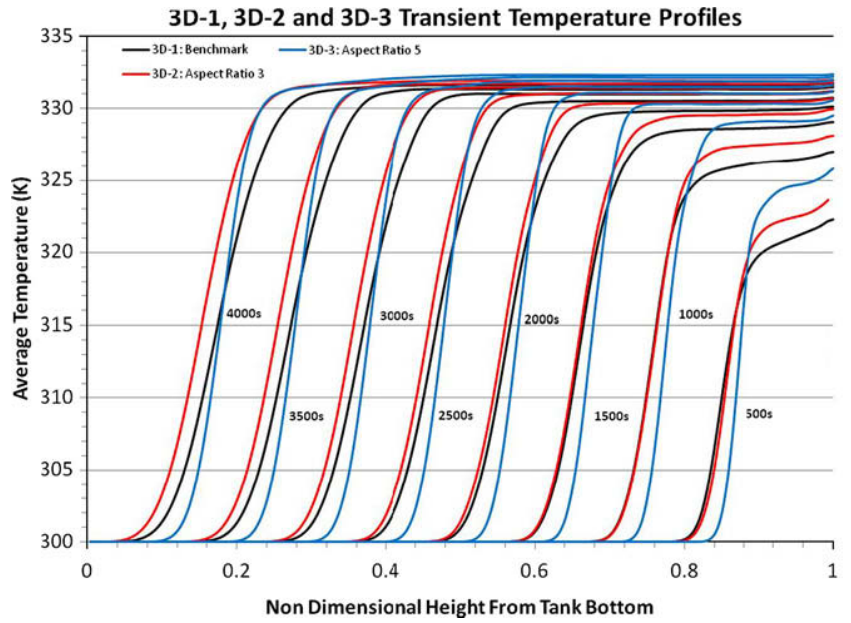

Fig. 6. Comparison of the evolutions of the vertical profiles of the averaged temperature in the tank for models 3D-1, 3D-2 and 3D-3.

model 3D-5 with a further increased mass flow rate of $0.15 \mathrm{~kg} / \mathrm{s}$. During the first $250 \mathrm{~s}$ of operation, it is seen that a much larger jet of hot water strikes the back wall and is deflected half way to the very bottom of the tank before diffusing. This prevents any degree of thermal stratification forming, ensuring the water in the tank stays well mixed at a quite early stage of the operation, making this configuration highly inefficient, as it would take many hours, maybe even days for the tank to be completely filled with the inlet temperature water.

The high degree of mixing observed in both models is especially evident if their vertical averaged temperature profiles are compared to those of model 3D-1, as shown in Fig. 9. The temperature in the top layer of water is much lower than that observed in the 

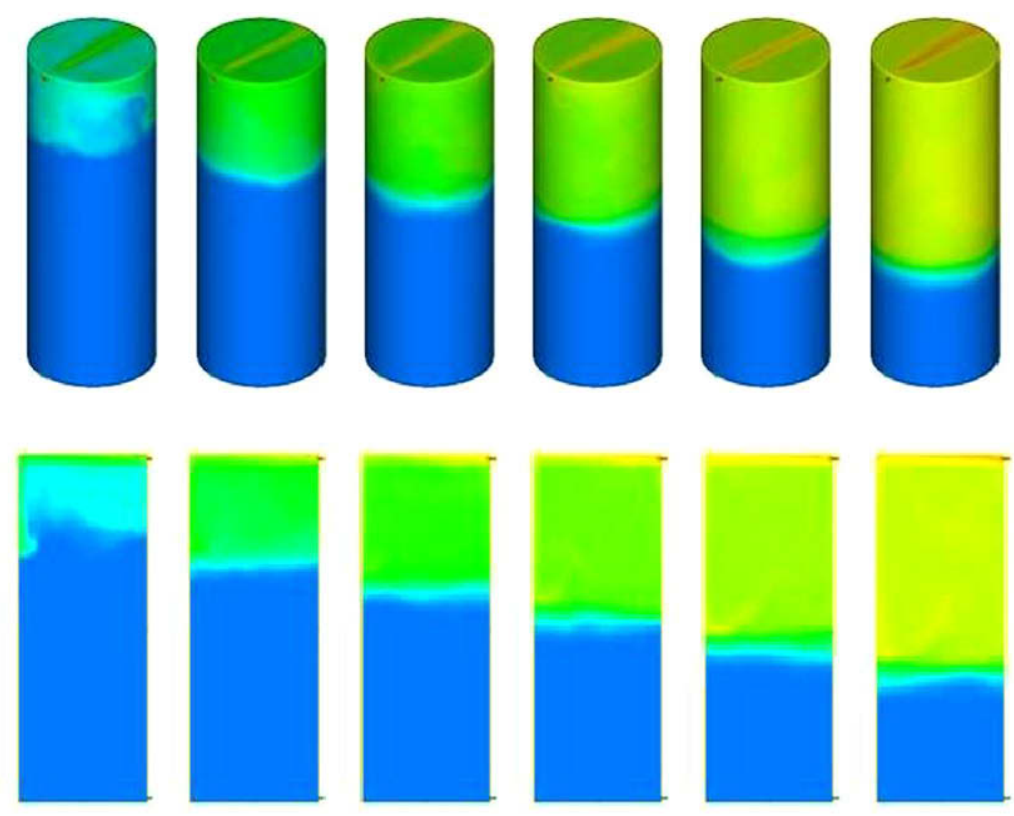

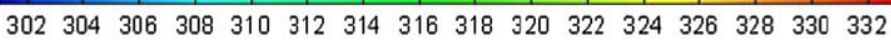

Fig. 7. Evolution of temperature contours of the 3D-4 model from $100 \mathrm{~s}$ to $1100 \mathrm{~s}$ with $200 \mathrm{~s}$ increment (from left to right): top row - three-dimensional, and bottom row sectioned two-dimensional.
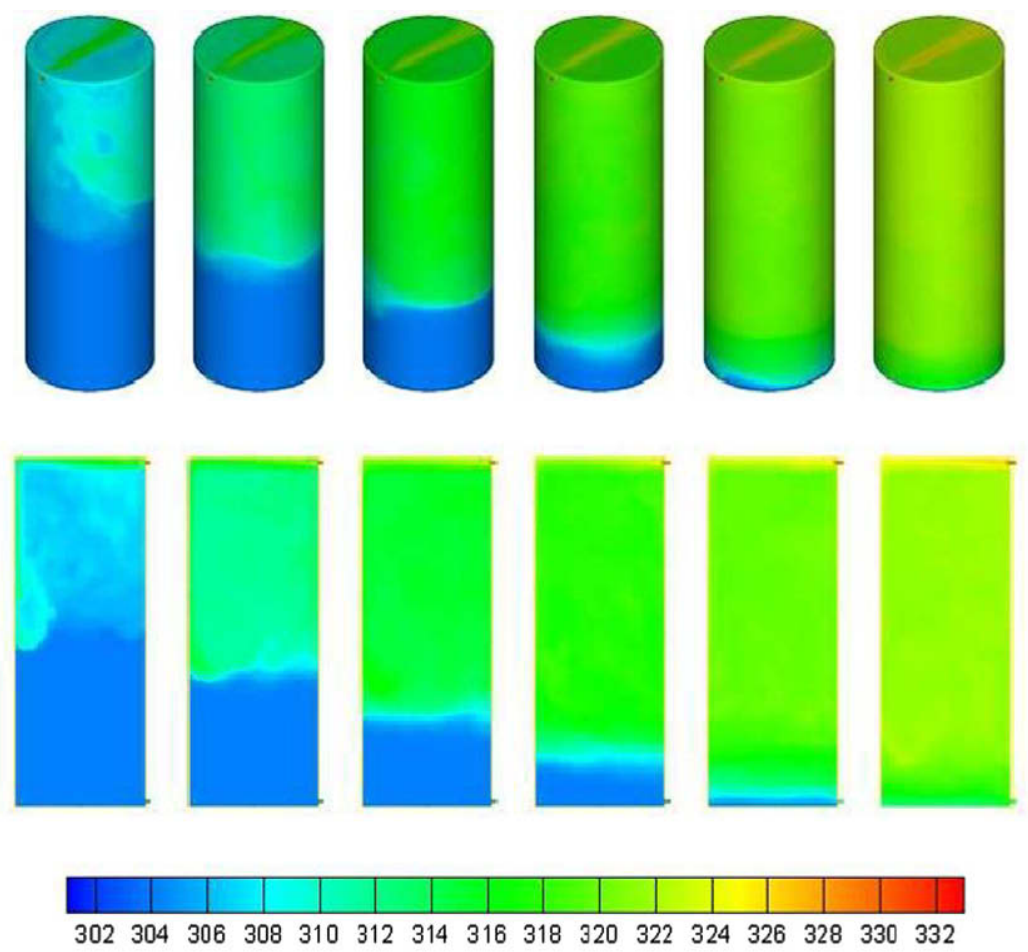

Fig. 8. Evolution of temperature contours of the 3D-5 model from $100 \mathrm{~s}$ to $1100 \mathrm{~s}$ with $200 \mathrm{~s}$ increment (from left to right): top row - three-dimensional, and bottom row sectioned two-dimensional.

base model, indicating a high degree of mixing. In addition, the gradients of the curves for both higher mass flow rates are much less linear than that for the base model, further indicating less defined thermocline thicknesses which are indicative of large degradations of thermal stratification.

\subsubsection{Inlet/outlet position models $3 D-6$ and $3 D-7$}

Models 3D-6 and 3D-7 have been developed to study the effect of the inlet/outlet positions on the thermal stratification within the tank. In these two models, inlet/outlets are located $150 \mathrm{~mm}$ and $300 \mathrm{~mm}$ from the top/bottom of the internal tank for models 


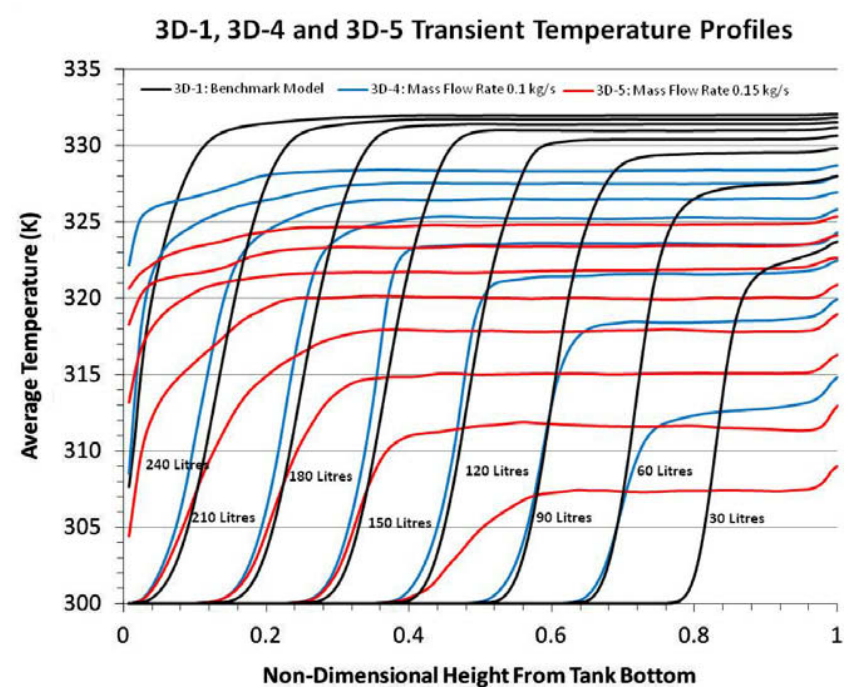

Fig. 9. Comparison of the evolutions of the vertical profiles of the averaged temperature in the tank for models 3D-1, 3D-4 and 3D-5.

3D-6 and 3D-7, respectively. The evolutions of both the 3D and the sectioned 2D temperature contours for these two model over the time period of $250-2750 \mathrm{~s}$ are presented in Figs. 10 and 11, respectively.

By examining the temperature contours presented in Fig. 10 for model 3D-6, it is seen that there is significant mixing in the first $250 \mathrm{~s}$ of operation. Although a small amount of mixing is cause by the inlet jet, its effects are probably only minor considering the limited mixing observed in model 3D-1 and the fact that both models 3D-6 and 3D- 1 share the same flow rate. The main source of mixing is due to the lower position of the hot water inlet and the consequent buoyancy effect on the hot inlet water as it enters the tank. The density of the hot water is much less than that of the cold water so buoyancy forces cause the hot water to rise and diffuse rapidly amongst the cold water causing a large degree of mixing. Once the layer of hot water develops in the top of tank and reaches the level of the hot water inlet, the effects of buoyancy induced mixing are minimized. The thermocline thickness is larger than that in model 3D-1, further indicating a comparatively higher degree of mixing.

It should also be noted that after $5000 \mathrm{~s}$ of operation, when a full cycle of water has passed through the tank, it is observed that there is still a significant region of cold water underneath the outlet. This is classified as a dead region and is highly undesirable in a hot water storage tank, as it represents a significant volume of water which has been rendered unusable, making the system highly inefficient.

Like model 3D-6, model 3D-7 also experiences a high level of buoyancy induced mixing. After $4000 \mathrm{~s}$ of operation, it is found that model 3D-7 has only just formed into three distinct layers, indicating an even larger degree of buoyancy induced mixing. In addition, the highly undesirable dead zone at the bottom of the tank is also presented in 3D-7 with even larger extent.

The high degree of mixing experienced by model 3D-6 and 3D-7 is also evident by comparing their temperature profiles to those of model 3D-1, as shown in Fig. 12. While the temperature profiles for model 3D-1 are almost linear with very steep gradients, those for models 3D-6 and 3D-7 are much more shallow and irregular. This shows that the conductive layers are much thicker and less uniform, indicating a much higher level of mixing. In addition, the hot layers of water formed at the top of the tank are of much lower temperatures, further showing some stratification degradation.

\subsection{Quantification of thermal stratification level}

Although the temperature contours and profiles discussed above give some indication of the level of thermal stratification, a quantitative parameter to measure the thermal stratification level will provide more conclusive and insightful information. In this
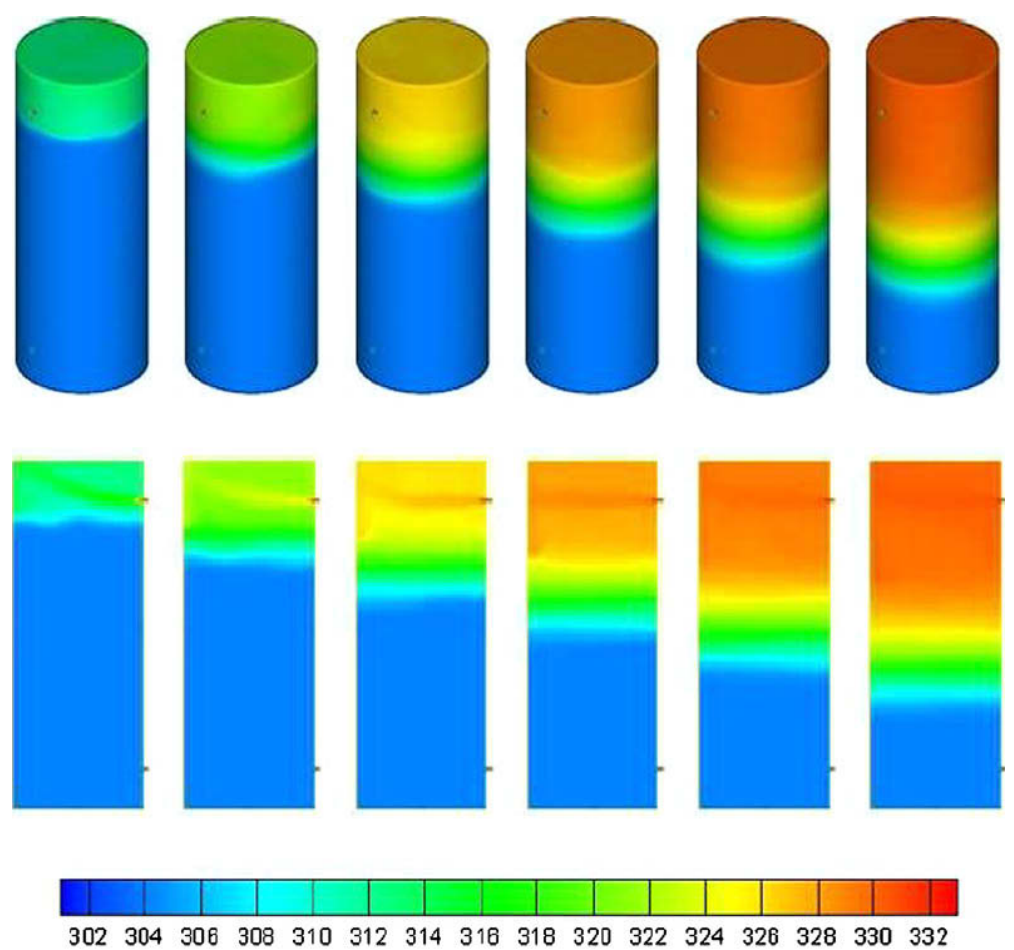

Fig. 10. Evolution of temperature contours of the 3D-6 model from $250 \mathrm{~s}$ to $2750 \mathrm{~s}$ with $500 \mathrm{~s}$ increment (from left to right): top row - three-dimensional, and bottom row sectioned two-dimensional. 

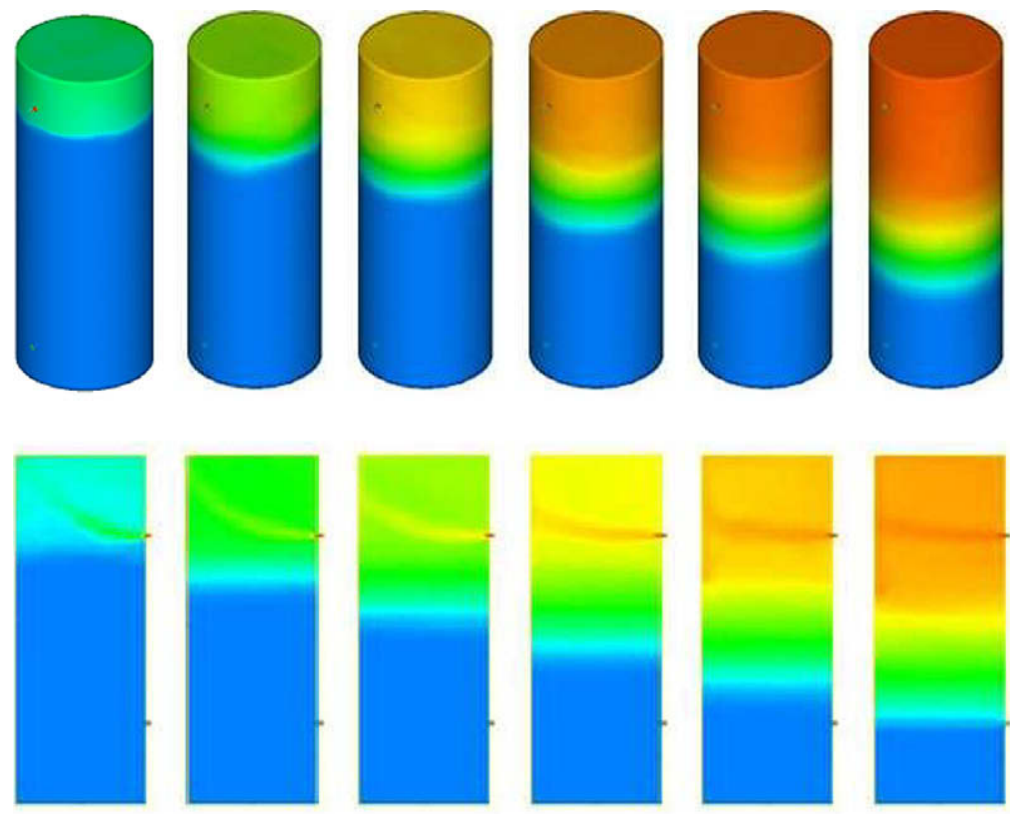

$\begin{array}{llllllllllllllll}302 & 304 & 306 & 308 & 310 & 312 & 314 & 316 & 318 & 320 & 322 & 324 & 326 & 328 & 330 & 332\end{array}$

Fig. 11. Evolution of temperature contours of the 3D-7 model from $250 \mathrm{~s}$ to $2750 \mathrm{~s}$ with $500 \mathrm{~s}$ increment (from left to right): top row - three-dimensional, and bottom row sectioned two-dimensional.

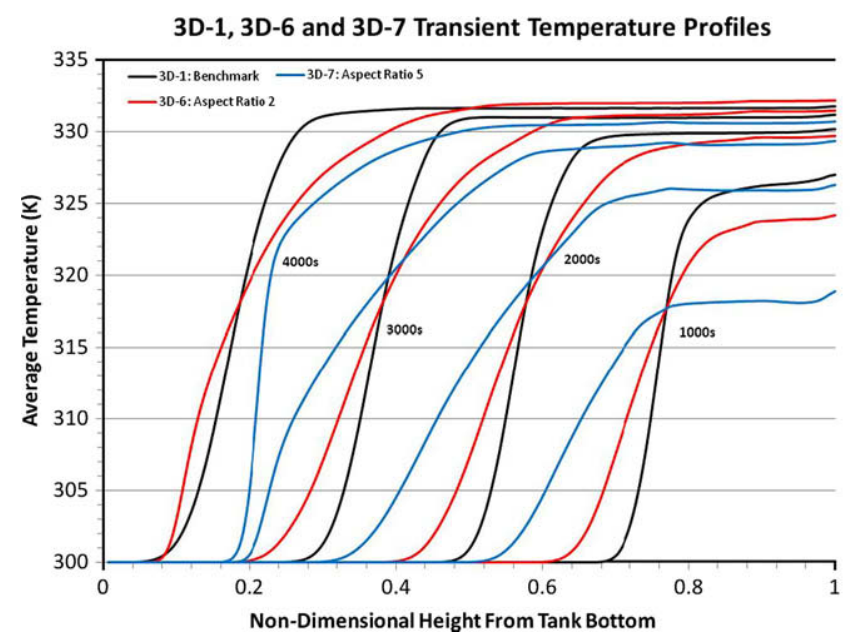

Fig. 12. Comparison of the evolutions of the vertical profiles of the averaged temperature in the tank for models 3D-1, 3D-6 and 3D-7.

paper, the level of thermal stratification will be quantified by the non-dimensional exergy $\zeta$ as introduced in Section 2. In addition, although the themocline thickness is not a quantitative measure, it has been shown that a thinner thermocline is indicative of a high degree of thermal stratification, and as such, thermocline thickness $\left(Z_{\mathrm{th}}, m\right)$ will also be used to further validate the quantitative measures.

In Table 2, a comparison of the non-dimensional exergy $\zeta$ and the thermocline thickness $Z_{\text {th }}$ is presented for the base model $3 \mathrm{D}-1$ and the aspect ratio models 3D-2 and 3D-3. As can be observed, $\zeta$ follow the same trend for all three models. As time progresses, the level of thermal stratification increases ( $\zeta$ approaches zero) once some initial mixing completes. This is because the hot water entering the tank quickly diffuses into the cold, meaning that the initial values of $\zeta$ increase. As more fluid is introduced, the thermocline region is pushed down, leaving a hot body of water at the top and thus reducing the mixing at the inlet zone. This gradual reduction in the mixing phenomena is represented by the decreasing $\zeta$.

The results discussed above show that the level of thermal stratification in a storage tank increases with the aspect ratio. In addition, the transient thermocline thicknesses for all models are of relatively small sizes, indicating that there is not a large degree of mixing within these models.

Unlike the aspect ratio models, the higher inlet/outlet mass flow rates of models 3D-4 and 3D-5 create a larger degree of mixing in the tank. This is evident by examining the values of $\zeta$ presented in Table 3. For higher inlet mass flow rates, $\zeta$ trends towards one, indicating a well mixed tank and a significant degradation of thermal stratification. A comparison of the thermocline thickness $Z_{\text {th }}$ also points to significant mixing, as it is almost the entire thickness of the tank for higher mass flow rates models 3D-4 and 3D-5. It is likely that the high flow rate models would take a long time to build enough hot fluid in the top of the tank to minimize mixing. However, the use of diffusers will likely be able to alleviate this problem.

Table 2

Comparison of the effects of the aspect ratio models on the thermal stratification.

\begin{tabular}{|c|c|c|c|c|c|c|}
\hline \multirow{2}{*}{$\begin{array}{l}\text { Time } \\
\text { (s) }\end{array}$} & \multicolumn{2}{|c|}{ Model 3D-1 } & \multicolumn{2}{|c|}{ Model 3D-2 } & \multicolumn{2}{|c|}{ Model 3D-3 } \\
\hline & $Z_{t h}(m)$ & $\zeta$ & $Z_{t h}(m)$ & $\zeta$ & $Z_{t h}(m)$ & $\zeta$ \\
\hline 500 & 0.21 & 0.464 & 0.22 & 0.398 & 0.27 & 0.336 \\
\hline 1000 & 0.34 & 0.334 & 0.37 & 0.263 & 0.48 & 0.221 \\
\hline 1500 & 0.47 & 0.274 & 0.51 & 0.204 & 0.15 & 0.178 \\
\hline 2000 & 0.32 & 0.241 & 0.17 & 0.172 & 0.14 & 0.154 \\
\hline 2500 & 0.17 & 0.220 & 0.17 & 0.150 & 0.15 & 0.139 \\
\hline 3000 & 0.17 & 0.204 & 0.16 & 0.134 & 0.15 & 0.128 \\
\hline 3500 & 0.17 & 0.192 & 0.17 & 0.121 & 0.16 & 0.120 \\
\hline 4000 & 0.18 & 0.182 & 0.17 & 0.111 & 0.16 & 0.113 \\
\hline
\end{tabular}


Table 3

Comparison of the effects of the inlet/outlet mass flow rate models on the thermal stratification.

\begin{tabular}{|c|c|c|c|c|c|c|}
\hline \multirow{2}{*}{$\begin{array}{l}\text { Time } \\
\text { (s) }\end{array}$} & \multicolumn{2}{|c|}{ Model 3D-1 } & \multicolumn{2}{|c|}{ Model 3D-4 } & \multicolumn{2}{|c|}{ Model 3D-5 } \\
\hline & $Z_{t h}(m)$ & $\zeta$ & $Z_{t h}(m)$ & $\zeta$ & $Z_{t h}(m)$ & $\zeta$ \\
\hline 200 & 0.12 & 0.643 & 0.34 & 0.766 & 0.67 & 0.875 \\
\hline 400 & 0.18 & 0.509 & 0.45 & 0.653 & 0.87 & 0.815 \\
\hline 600 & 0.23 & 0.426 & 0.56 & 0.579 & 1.03 & 0.760 \\
\hline 800 & 0.29 & 0.372 & 0.67 & 0.529 & 1.19 & 0.708 \\
\hline 1000 & 0.34 & 0.334 & 0.78 & 0.492 & 1.27 & 0.671 \\
\hline 1200 & 0.39 & 0.305 & 0.88 & 0.462 & 1.27 & 0.671 \\
\hline 1400 & 0.45 & 0.283 & 0.99 & 0.435 & 1.27 & 0.697 \\
\hline 1600 & 0.50 & 0.265 & 1.09 & 0.412 & 1.27 & 0.726 \\
\hline
\end{tabular}

Table 4

Comparison of the effects of the inlet/outlet position models on the thermal stratification.

\begin{tabular}{|c|c|c|c|c|c|c|}
\hline \multirow{2}{*}{$\begin{array}{l}\text { Time } \\
\text { (s) }\end{array}$} & \multicolumn{2}{|c|}{ Model 3D-1 } & \multicolumn{2}{|c|}{ Model 3D-6 } & \multicolumn{2}{|c|}{ Model 3D-7 } \\
\hline & $Z_{t h}(m)$ & $\zeta$ & $Z_{t h}(m)$ & $\zeta$ & $Z_{\text {th }}(m)$ & $\zeta$ \\
\hline 500 & 0.21 & 0.464 & 0.28 & 0.615 & 0.39 & 0.760 \\
\hline 1000 & 0.34 & 0.334 & 0.41 & 0.451 & 0.52 & 0.611 \\
\hline 1500 & 0.47 & 0.274 & 0.54 & 0.365 & 0.65 & 0.513 \\
\hline 2000 & 0.32 & 0.241 & 0.67 & 0.313 & 0.78 & 0.445 \\
\hline 2500 & 0.17 & 0.220 & 0.40 & 0.279 & 0.90 & 0.397 \\
\hline 3000 & 0.17 & 0.204 & 0.39 & 0.255 & 0.99 & 0.363 \\
\hline 3500 & 0.17 & 0.192 & 0.40 & 0.236 & 0.61 & 0.359 \\
\hline 4000 & 0.18 & 0.182 & 0.35 & 0.224 & 0.35 & 0.391 \\
\hline
\end{tabular}

A comparison of the non-dimensional exergy and thermocline thickness for the base model 3D-1 and the inlet/outlet position models 3D-6 and 3D-7, as presented in Table 4, identifies a similar trend to that observed for the aspect ratio models 3D-2 and 3D-3. There is some initial mixing until a body hot water builds in the top of the tank. At this point the level of thermal stratification within the tank begins to build, resulting in decreasing values of $\zeta$. In these cases, however, modifying the tank geometry has an adverse effect on the level of thermal stratification achieved even though it is improving with time. As the inlet and outlet move further away from the top and the bottom of the tanks, the tanks are subject to increasing stratification degradation. This degradation in the level of thermal stratification is further indicated by the values of $Z_{\mathrm{th}}$, which show that the transient thermocline thicknesses for models 3D-6 and 3D-7 are much larger than that of 3D-1, representing a much higher level of mixing.

It is possible to develop a time averaged non-dimensional exergy $\bar{\zeta}$ as a single overall measure of the thermal stratification level in the tank. The calculated values of $\bar{\zeta}$ for all models considered are presented in Figs. 13-15, respectively. It should be noted that models 3D-4 and 3D-5 have been calculated on a simulation time of $1600 \mathrm{~s}$ while all other models have been calculated on a simulation time of 4000 s. From Fig. 13 where the effect of the aspect ratio on

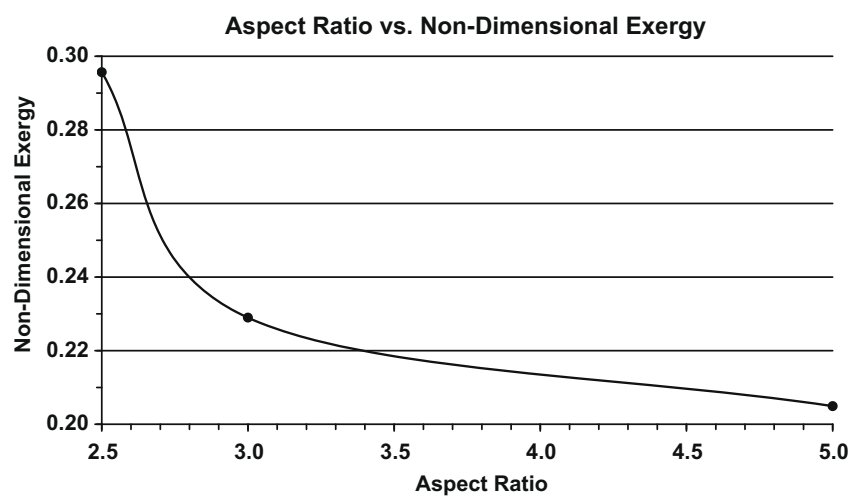

Fig. 13. Effects of the aspect ratio on thermal stratification.

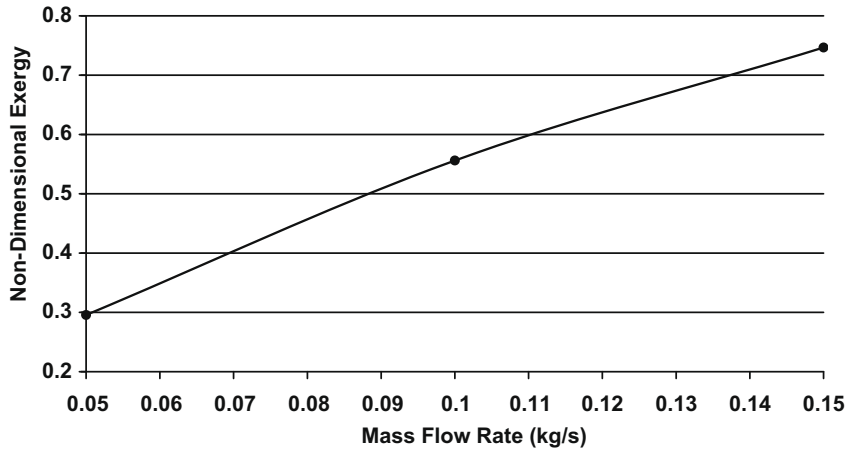

Fig. 14. Effects of the inlet/outlet mass flow rate on thermal stratification.

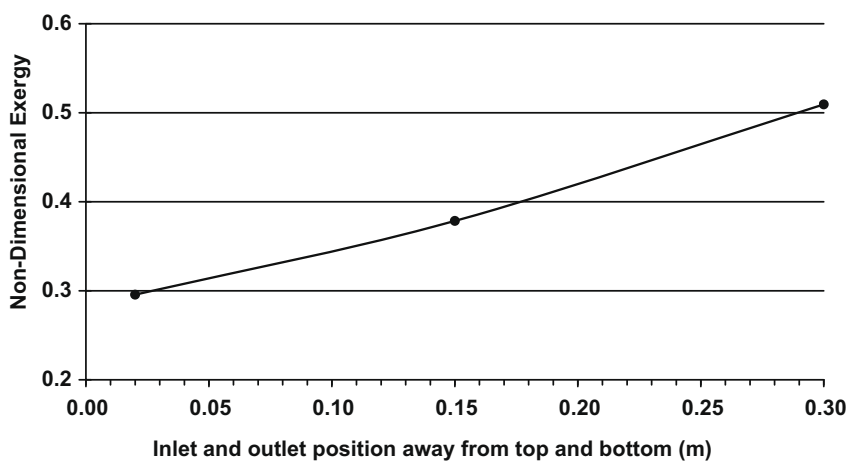

Fig. 15. Effects of the inlet/outlet position on thermal stratification.

thermal stratification level is shown, it is seen that the degree of thermal stratification in a vertical storage tank increases parabolically with the aspect ratio. This improvement with increasing aspect ratio occurs mostly in the range of $A R=0$ to $A R=4$. After $\mathrm{AR}=4$, the improvements become marginal. Thus it can be approximated that the optimum aspect ratio for a vertical thermal storage tank is 3.5 , as larger aspect ratio tanks are more expensive to 
construct but offer marginal improvement of thermal stratification. From Fig. 14 where the effect of the mass flow rate is shown, it is seen that the degree of thermal stratification decreases almost linearly with the mass flow rate. Hence, the mass flow rate should be kept as low as possible for given geometry. From Fig. 15 where the effect of the inlet/outlet position is shown, it is seen that the level of thermal stratification decreases almost linearly as the inlet and outlet position away from the top and bottom of the tank is increased. This indicates that for maximum thermal stratification, the inlet and outlets should be kept as close as possible to the top and bottom of the tank, respectively.

\section{Conclusions}

The three-dimensional numerical simulation results presented in this paper can be summarized as follows:

- A higher aspect ratio of the storage tank leads to a higher degree of thermal stratification as when the aspect ratio is increased from 2.5 to 3 , a $22.57 \%$ increase in thermal stratification will be achieved, and when this aspect ratio is further increased from 2.5 to 5 , a $30.69 \%$ increase in thermal stratification will be attained. It is also found that the aspect ratio models experience a small degree of initial mixing until a layer of hot water built up in the top of the tank. After this the tanks experience little thermal stratification degradation. Although a considerable gain in performance is achieved by increasing the tank's aspect ratio, the dimensions of a large aspect ratio tank are often impractical. A 250-L tank with an aspect ratio of 5 is $2 \mathrm{~m}$ tall and $0.4 \mathrm{~m}$ in diameter, which can make it unsuitable to install in modern home. The ideal aspect ratios of storage tanks should be 3.5 , as larger aspect ratio tanks are more expensive to construct but offer marginal improvement of thermal stratification. In addition, as the aspect ratio of a tank increases, so does its surface area. Although not studied in this paper, as heat losses are proportional to the surface area of a tank, a high aspect ratio tank may need a higher degree of thermal insulation in order to prevent heat losses that lower efficiency and create natural convection currents that can destroy thermal layers.

- A high inlet/outlet mass flow rate will have a detrimental effect on the level of thermal stratification. High inlet/outlet flow rates create significantly strong jets that strike the back wall of the tank before diffusing into a large area, which destroys thermal layers and heavily reduces the level of thermal stratification. When the mass flow rate is increased from $0.05 \mathrm{~kg} / \mathrm{s}$ to $0.1 \mathrm{~kg} /$ $\mathrm{s}$, it was found that a $32.46 \%$ reduction in the level of thermal stratification occurs, and when the mass flow rate is further increased from $0.05 \mathrm{~kg} / \mathrm{s}$ to $0.15 \mathrm{~kg} / \mathrm{s}$, a $77.85 \%$ reduction in the level of thermal stratification occurs. Hence, the inlet/outlet mass flow rates should be kept as low as possible to minimize mixing. In a thermosiphon solar water heater, flow rates are usually in the vicinity of $0.05 \mathrm{~kg} / \mathrm{s}$, small enough to cause little mixing. However, if higher inlet/outlet flow rates are to be experienced, significantly more mixing will be expected. In these cases, to maintain high level of thermal stratification, other approaches such as diffusers should be employed.

- Similar to the inlets/outlet mass flow rates, the inlet/outlet position negatively impacts upon the level of thermal stratification. When the inlet/outlet is moved to the position $150 \mathrm{~mm}$ away from the top/bottom of the tank, a $28.01 \%$ decrease in the level of thermal stratification occurs, and when the inlet/outlet is fur- ther moved to the position $300 \mathrm{~mm}$ away from the top/bottom of the tank, a $72.26 \%$ decrease in the level of thermal stratification will occur. However, the mechanism in which the mixing occurs is different from that presented in high mass flow rate models. High mass flow rates cause jets that introduce mixing, however when considering the position of the inlet/outlet, the buoyancy driven flow creates a considerable reduction on the thermal stratification levels within the storage tank. If the hot inlet water enters low in the tank, buoyancy effects causes it to rise rapidly through the cold water causing significant mixing as the hot water diffuses. The optimal position for the inlet/outlet is at the very top/bottom of the tank.

\section{Acknowledgements}

The financial support from the Ministry of Science and Technology, China (973 Program - the National Key Basic Research Scheme, Grant No. 2007CB216405), the National Natural Science Foundation of China (Grant No. 50879074), and the Natural Science Foundation of Yunnan Province of China (Grant Nos.: 2007C0016Z, 2008GA014) is gratefully acknowledged.

\section{References}

[1] Garg HP, Mullick SC, Bhargava AK. Solar thermal energy storage. Dordrecht: D. Reidel Publishing Company; 1985.

[2] Furbo S, Andersen E, Thur A, Shah LJ, Andersen KD. Performance improvement by discharge from different levels in solar storage tanks. Sol Energy 2005:79:431-9.

[3] Hegazy AA, Diab MR. Performance of an improved design for storage-type domestic electrical water-heaters. Appl Energy 2002;71:287-306.

[4] Hegazy AA. Effect of inlet design on the performance of storage-type domestic electrical water heaters. Appl Energy 2007;84:1338-55.

[5] Lavan Z, Thompson J. Experimental study of thermally stratified hot water storage tanks. Sol Energy 1977;19:519-24.

[6] Bouhdjar A, Harhad A. Numerical analysis of transient mixed convection flow in storage tank: influence of fluid properties and aspect ratios on stratification. Renew Energy 2002:25:555-67.

[7] Altuntop N, Kilik Z, Ozceyhan V, Kincay O. Effect of water inlet velocity on thermal stratification in a mantled hot water storage tank. Int J Energy Res 2006;30:163-76.

[8] Perez IR. Unsteady laminar convection in cylindrical domains: numerical studies and application to solar water storage tanks, Ph.D. Thesis. Barcelona: UPC - Barcelona Tech; 2006.

[9] Ievers S. Three dimensional flow dynamics in a hot water storage tank, B. Eng. Thesis. Townsville, Australia: School of Engineering, James Cook University; 2008.

[10] Lin W, Lu E, Wang D. The solar water heating system with natural circulation assisted by an auxiliary electric heater-performance modelling. Energy Convers Manage 1991;31:409-18.

[11] Lin W, Lu E. Parametric studies of thermosyphon solar water systems with electric heaters. Energy 1992:17:397-403.

[12] Lin W, Lu E. Analyzing the effect of the LAEH in the storage tank on the performance of a TSAEH. Int J Energy Res 1992;16:459-66.

[13] Shin MS, Kim HS, Jang DS, Lee SN, Lee YS, Yoon HG. Numerical and experimental study on the design of a stratified thermal storage system. Appl Therm Eng 2004;24:17-27.

[14] Spall RE. A numerical study of transient mixed convection in cylindrical thermal storage tanks. Int J Heat Mass Trans 1998;41:2003-11.

[15] Shah LJ, Furbo S. Entrance effects in solar storage tanks. Sol Energy 2003:75:337-48.

[16] ANSYS. Fluent. <http://www.Fluent.com/.2008>.

[17] Bahnfleth WP, Musser A. Thermal performance of a full-scale stratified chilledwater thermal storage tank. ASHRAE Trans 1998;104:377-88.

[18] Khurana TK, Prasad BVSSS, Ramamurthi K, Murthy SS. Thermal stratification in ribbed liquid hydrogen storage tanks. Int J Hydrogen Energy 2006;31:2299-309.

[19] Rosen MA. The exergy of stratified thermal energy storages. Sol Energy $2001 ; 71: 173-85$.

[20] Rinnai. Rinnai hot water system specifications. 2008. <http://www.rinnai. com.au/solar/specifications.asp?whs=home\&pg=0>. 